Notch signaling pathway is activated dynamically during evolution playing significant role in cell fate determination and differentiation. It has been known that alterations of this pathway may lead to human malignancies, including gastric cancer. Despite a decline in the overall incidence, this disease still remains an important global health problem. Therefore, a better understanding of the molecular alterations underlying gastric cancer may contribute to the development of rationally designed molecular targeted therapies. It has been reported that Notch1 receptor could become a prognostic marker of gastric cancer and novel target for gastric cancer therapy. Among the novel and targeted approaches for the treatment of gastric cancer is also the process of Notch receptors regulation by specific microRNA. $\gamma$-secretase inhibitors are also taken into consideration.

Key words: gastric cancer, Notch, miR-34, COX-2, $\gamma$-secretase inhibitors.

\section{Role of Notch signaling pathway in gastric cancer pathogenesis}

\author{
Marlena Brzozowa, Łukasz Mielańczyk, Marek Michalski, \\ Łukasz Malinowski, Grażyna Kowalczyk-Ziomek, Krzysztof Helewski, \\ Marzena Harabin-Słowińska, Romuald Wojnicz
}

Chair and Department of Histology and Embryology, Faculty of Medicine and Dentistry in Zabrze, Medical University of Silesia, Katowice, Poland

\section{Introduction}

Despite a decline in the overall incidence, gastric cancer still remains an important global health problem. About $95 \%$ of gastric cancers are caused by adenocarcinoma originating from the glandular cells of the stomach lining [1]. According to Lauren's classification there are two main types of gastric adenocarcinoma: intestinal and diffuse [2]. The intestinal type of gastric cancer is characterized by cohesive neoplastic cells forming gland-like tubular structures and is closely associated with environmental and dietary risk factors such as Helicobacter pylori infection and high-salt diet. The well-known and accepted paradigm for pathogenesis of this type of gastric cancer is a multistep progression from chronic gastritis to gastric atrophy to intestinal metaplasia to dysplasia [2]. The histology of diffuse gastric cancer is characterized by poorly differentiated cells and no glandular structures. It seems that the major etiologic risk factor is also $\mathrm{H}$. pylori infection [2].

In westernized countries, a large number of gastric cancer patients are diagnosed when the tumor is at an unresectable stage. Currently, the only solution for these patients is systemic chemotherapy which prolongs survival without quality of life compromise. Unfortunately, survival of patients with advanced gastric cancer treated with palliative chemotherapy remains low. Therefore, a better understanding of the molecular alterations underlying gastric cancer pathogenesis is important from the clinical point of view. It may contribute to development of the rationally designed molecular targeted therapies, which interfere with the multiple signaling pathways involved in cancer cell biology [3-7]. One of these pathways - the Notch signaling pathway - is activated dynamically during evolution and plays a crucial role in the fate of cell differentiation during embryonic development. On the other hand, alterations of this pathway may lead to abnormalities including malignant diseases, e.g. gastric cancer [8].

In this paper we review the role of the Notch signaling pathway in gastric cancer pathogenesis.

\section{The Notch signaling pathway}

The Notch pathway is an evolutionarily conserved cell signaling mechanism that participates in many cellular processes including proliferation, differentiation, apoptosis and stem cell maintenance [8] (Fig. 1). There are four Notch receptors: Notch1, 2, 3 and 4. Each of them is synthesized as a precursor form composed of extracellular, transmembrane and intracellular domains. Within the Golgi apparatus, the precursor Notch protein is cleaved by a furin-like convertase to generate two subunits. One subunit contains most of the extracellular domain and the second subunit consists of the rest of the extracellular and transmembrane domains. The Notch ligand family comprises five members: Jagged1/2 and Delta-like 1/3/4 (DLL1/3/4), which are also single- 


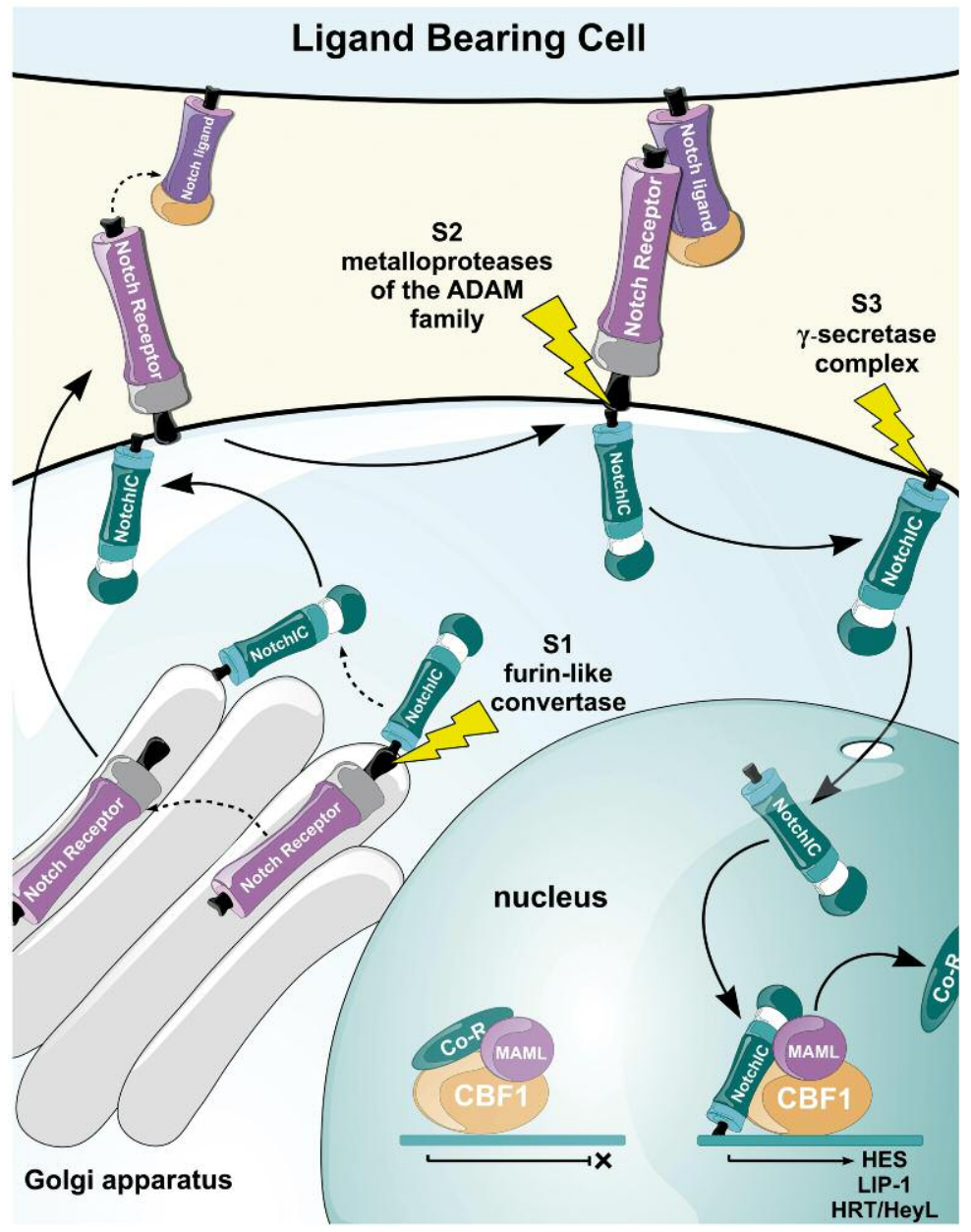

Fig. 1. Notch signaling pathway - details in the text

pass type I transmembrane proteins. The extracellular domain of the Notch receptor has been shown to contain 36 EGF- like repeats $[8,9]$. Ligand binding to EGF-like repeats unfolds the negative regulatory region (NRR) permitting the next cleavage by metalloproteases of the ADAM family [8]. During the next step, $\gamma$-secretase complex executes an intramembrane cleavage releasing the Notch intracellular domain (NotchIC or NICD) which undergoes translocation to the nucleus [10]. It has been reported that for activation of Notch signaling the Mastermind-like family of proteins (MAML1/2/3) are required. MAML forms a ternary complex with CBF1-NotchIC via direct interaction with NotchIC. Then, the ternary complex composed of CBF1-NotchIC-MAML acts as a transcriptional activator, resulting in Notch target gene transcription. Among the primary targets there are several genes belonging to the basic helix-loop-helix (bHLH) family. Following Notch activation at least two families of bHLH proteins are induced: the Hairy/Enhancer-of-Split (HES) family and the Hairy-Related Transcription factor (HRT) family, which are known to be transcriptional repressors [11].

Although a great number of Notch cellular responses occur as a result of activation of the canonical Notch pathway described above, there are other proteins that may also act as Notch ligands and trigger Notch induction. In this noncanonical pathway other transmembrane proteins are involved. It is worth noting that these proteins have EGF-like repeats too. Among them we may list Dner, F3/contactin-1 and NB-3/contactin-6. However, these Notch ligands bind Notch receptors with less affinity than the conventional Notch ligands because they do not have a DSL region in their structure [12].

\section{The oncogenic role of the Notch signaling pathway in gastric cancer pathogenesis}

The latest studies have revealed that in normal gastric mucosa Notch signaling is involved in the process of differentiation of gastric epithelium into foveolar glands. The results of these studies have demonstrated that expression of Notch1, Notch3, Jagged1, Jagged2 and Hes1 was detected in the isthmus area of normal mucosa where putative gastric stem cells are found [13] (Table 1). It should be noted here that Notch signaling is associated with glandular differentiation not only of normal gastric mucosa but also of gastric carcinoma cells. Notch receptors, e.g. Notch1, Notch2 and Notch3, and Notch ligands such as Jagged 1 and Jagged 2 have been detected in samples of human gastric cancer tissues too [13]. For example, expression of Notch1 appears in both premalignant and cancer tissues. It is especially observed in samples of intestinal metaplasia and well-differentiated intestinal type of gastric cancer. Thus it is reasonable to consider that Notch1 may play a crucial role in both promoting metaplastic tran- 
Table 1. Notch expression in normal gastric mucosa

$\begin{array}{lll}\text { Notch receptors and Notch ligands } & \text { Tissue-specific expression } & \text { The role in gastric histology } \\ \text { Notch1 } & \text { isthmus area of normal mucosa where } & \text { differentiation of gastric epthelium into foveolar glands } \\ \text { Notch2 } & \text { putative gastric stem cells are found } & \\ \text { Jagged1 } & \\ \text { Jagged2 } & \end{array}$

Table 2. Notch expression in different types of gastric cancer

\begin{tabular}{|c|c|c|}
\hline Notch receptors and Notch ligands & Type of gastric cancer & The role of Notch proteins in gastric cancer pathogenesis \\
\hline Notch1 & $\begin{array}{l}\text { premalignant and cancer tissue: } \\
\text { intestinal metaplasia and well } \\
\text { differentiated intestinal type } \\
\text { of gastric cancer }\end{array}$ & $\begin{array}{l}\text { crucial role in promoting metaplastic transition of gastric } \\
\text { epithelial cells and in maintaining constant proliferation } \\
\text { of intestinalized epithelial cells }\end{array}$ \\
\hline Notch2 & intestinal and diffuse type & - \\
\hline DLL1 & diffuse and mixed type & - \\
\hline $\begin{array}{l}\text { Notch3 } \\
\text { Jagged }\end{array}$ & intestinal type & - \\
\hline
\end{tabular}

sition of gastric epithelial cells and in maintaining constant proliferation of intestinalized epithelial cells $[14,15]$. The activated form of the Notch1 receptor has promoted colony-forming ability and xenografted tumor growth of human stomach adenocarcinoma SC-M1 cells [16]. Piazzi et al. have analyzed the expression of Notch1 and its ligand DLL1 in eight gastric cancer cell lines. It is worth noting that DLL1 expression was not detected in KATOIII, SNU601, SNU719 or AGS cells, which was probably associated with promoter hypermethylation. In contrast, 5-aza-2' deoxycytidine caused upregulation of DDL1. The increase in DLL1 expression was correlated with activation of Notch1 signaling, with an increase in cleaved NICD domain and Hes1, and also with downregulation in Hath1. Moreover, in gastric cancer patients a strong correlation between expression of DLL1 and Hes1 has been observed. It is also worth noting that DLL1 methylation and Hath1 expression were associated with the diffuse and mixed type of gastric cancer. What is important, none of the samples from INS-GAS mice infected with $\mathrm{H}$. pylori, a model of the intestinal type of gastric cancerogenesis, demonstrated promoter methylation of DLL1 [16]. In contrast, expression of Notch3 and Jagged2 is connected with the intestinal type of gastric cancer and better histological differentiation [13] (Table 2). Paradoxically, patients with overexpression of Notch3 and Jagged 2 genes have shown a better outcome than those with cancers demonstrating lower expression. Why? Kang et al. thought that the first effects of Notch signaling may take place when cells undergo malignant transformations. During the second step, cancer cells escape from an undifferentiated progenitor state to become differentiated cells, followed by cell death [13]. Yeah et al. revealed that another ligand, Jagged1, is also connected with gastric cancer pathogenesis. Expression of this protein was clearly correlated with aggressiveness, which means that patients with Jagged1 expression had a poor survival rate [17]. Among other signaling pathways involved in gastric cancer progression STAT3 and Twist pathways are worthy of consideration. In SC-M1 cells Twist and phosphorylated STAT3 levels were promoted by the activated Notch1 receptor. Moreover, overexpression of $\mathrm{N} 1 \mathrm{IC}$ enhanced the interaction between nuclear STAT3 and Twist promoter in cancer cells. Colony formation, migration and invasion abilities of SC-M1, AGS and KATOIII cells were also promoted by N1IC by the way of STAT3 phosphorylation and Twist expression. It should also be noted that the N1IC-promoted tumor growth and lung metastasis of SC-M1 cells in mice were suppressed by the STAT3 inhibitor JSI-124 and Twist knockdown [18]. In endoscopic biopsies of gastric noncancerous mucosa with mild inflammatory changes Notch2 expression and its translocation to the nucleus remain at a very low level. In gastric cancer lines it became frequent, which may suggest a correlation of Notch2 expression and its proteolytic activation with pathogenesis of gastric cancer [14]. It has been reported that constitutive expression of Notch2 intracellular domain (N2IC) impacts on migration, invasion, colony formation and wound-healing abilities of SC-M1 cells. These mentioned abilities are inhibited by Notch2 knockdown. In contrast, a study with the use of AGS and AZ521 cancer cells demonstrated that knockdown of Notch2 may be associated with cancer progression [19]. The importance of the Notch signaling pathway in the growth and survival of Notch2-activating gastric cancer cells was evaluated by cleavage inhibition of Notch receptors with two $\gamma$-secretase inhibitors (GSIs), L685,458 and DAPT [13]. As revealed by the studies, the GSIs may inhibit cell growth and induce apoptosis in such cancers as hepatoma, breast cancer, pancreatic cancer and myeloma [20-22]. In this context it should be emphasized that the Notch signaling pathway widely participates in cellular physiology. Therefore, it is likely that inactivation of $\gamma$-secretases may lead to pathological dysfunction of different tissues and organs. Moreover, GSIs do not target the proteins connected with Notch signaling only. It must be mentioned that GSIs may also target proteases and therefore may have widespread adverse effects in vivo because proteases are implicated in a wide array of cellular processes [20, 23]. The studies of Sun et al. have revealed that although Hes1 expression and its nuclear translocation are inhibited by GSIs, both gastric cancer cells AGS and BGC823 showed neither growth arrest nor cell death. This suggests that Notch2 signaling may not be the crucial molecular machinery for the 
maintenance and survival of gastric cancer cells. Probably, other powerful signaling pathways may compensate Notch signaling when its activity is suppressed. In this context, simply blocking Notch signaling may not achieve the promising inhibitory outcome in an experimental system of gastric cancer [14].

Activation of the Notch1 signaling pathway could promote progression of gastric cancer at least in part through cyclooxygenase-2 (COX-2) $[24,17]$. The colony forming, migration, and invasion abilities enhanced by N1IC were suppressed in SC-M1 cells after treatment with the COX-2 inhibitor NS-398 or COX-2 knockdown. These processes were restored by prostaglandin PGE2 or exogenous COX-2 [17]. Murata et al. have demonstrated that COX-2 overexpression in gastric cancer is highly correlated with tumor invasion into the lymphatic vessels in the gastric wall and metastasis to the lymph nodes [25]. Fosslien et al. reported that COX-2 produced both by cancer cells and by cells from the tumor microenvironment contribute to new vessel formation. In other words, it may have an impact on the process of tumor angiogenesis [26]. Therefore, it may explain how selective COX-2 inhibition reduces tumor growth, where the tumor COX-2 gene has been silenced by methylation [24]. The last studies of Tseng et al. have revealed that the active intracellular domain of Notch2 (N2IC) can bind to COX-2 promoter and may induce COX-2 expression through a CBF1-dependent manner in SC-M1 cells [19]. The capacity of N2IC to enhance the tumor progression in SC-M1 cells may be inhibited by COX-2 knockdown. Another possibility to enhance tumor progression is treatment with NS-398, which is a known COX-2 inhibitor [19].

Ji et al. suggest that regulation of the Notch receptors by specific microRNA could become a novel approach for gastric cancer treatment. Their studies have demonstrated that miR-34 restoration in gastric cancer Kato III cells reduces expression of target genes, e.g. Notch, Bcl-2 and HMGA2 [27, 28]. miR-34 is composed of three processed miRNAs. In this family miR-34a is encoded by its own transcript, whereas miR$34 \mathrm{~b}$ and miR-34c share a common primary transcript. It is now recognized that expression of miR-34a was uncommon in such cancers as pancreatic cancer, osteosarcoma, breast cancer and non-small cell lung cancer [29-32]. The inactivation of miR-34a was also identified in cell lines derived from some tumors including lung, breast, colon, kidney, bladder, pancreas and melanoma. In malignant melanoma, colorectal cancer and oral squamous cell carcinoma the inactivation of miR$34 \mathrm{~b}$ and miR-34c has been observed - probably by the mechanism of CpG methylation [33-35]. Recent studies have revealed that ectopic miR-34 is associated with inhibition of cell proliferation, colony formation and cell cycle G1 arrest $[35,36]$. Re-expression of miR-34a may induce apoptotic cell death, which was probably suppressed by inactivation of the p53 gene. It is worth noting that miR-34a could target several mRNAs, e.g. SIRT1, Bcl-2, N-myc, or cyclin D1, which leads to the translational repression of these genes $[36,37]$.

In summary, Notch signaling is clearly involved in the pathogenesis of gastrointestinal tumors such as gastric and colon cancer. Similarly as in the differentiation process, its effect in carcinogenesis in the gastrointestinal tract is probably cell type specific and circumstance dependent. Why? Because Notch proteins suppress malignant transformation in some tissues and promote malignancy in others. An improved understanding of the Notch-mediated signaling pathway in tissues under physiological conditions as well as in those undergoing malignant transformation is essential from the clinical point of view because it may lead to novel cancer therapeutics.

\section{References}

1. Klusek J, Głuszek S, Kozieł D. Co nowego w profilaktyce nowotworów układu pokarmowego - przegląd piśmiennictwa 2009-2010. Przegl Gastroenterol 2011; 6: 78-84.

2. Hamilton JP, Meltzer SJ. A review of the genomics of gastric cancer. Clin Gastr Hep 2006; 4: 416-25.

3. Gravalos C, Jimeno A. HER2 in gastric cancer: a new prognostic factor and a novel therapeutic target. Ann Oncol 2008; 19: 1523-9.

4. Wagner AD, Grothe W, Haerting J, Kleber G, Grothey A, Fleig WE. Chemotherapy in advanced gastric cancer: a systematic review and meta- analysis based on agregate date. J Clin Oncol 2006; 24 2903-9.

5. Staniuk T, Jankowski M, Zegarski W, Małkowski B, Kula Z. Ocena przydatności badania FDG-PET/CT w diagnostyce i kwalifikacji do leczenia operacyjnego zaawansowanego raka żołądka. Wspolczesna Onkol 2010; 14: 302-9

6. Nowara E, Boratyn-Nowicka A, Polakiewicz-Gilowska A, Drosik A, Kustra M, Huszno J. Chemotherapy for gastric cancer patients- time for personalization in medicine? Wspolczesna Onkol 2012; 16: 86-89.

7. Huszno J, Mrochen-Domin I, Zembala-Nożyńska E, Tukiendorf A, Lange D, Nowara E. Mucin secretion activity of gastric cancer as a prognostic factor: a clinicopathological analysis. Wspolczesna Onkol 2012; 16: 159-64.

8. Koch U, Radtke F. Notch and cancer: a double- edged sword. Cell Mol Life Sci 2007; 64: 2746- 2762.

9. Borgrefe T, Oswald F. The Notch signaling pathway: Transcriptional regulation at Notch target genes. Cell Mol Life Sci 2009; 66: 1631-46.

10. Kopan R, Ilagan MX. The canonical Notch signaling pathway: unfolding the activation mechanism. Cell 2009; 137: 216-33.

11. Leong KG, Karsan A. Recent insights into the role of Notch signaling in tumorigenesis. Blood 2006; 107: 2223-33.

12. Bolós V, Blanco M, Medina V, Aparicio G, Díaz-Prado S, Grande E. Notch signaling in cancer stem cells. Clin Transl Oncol 2009; 11: 11-9.

13. Kang H, An HJ, Song JY, Kim TH, Heo JH, Ahn DH, Kim G. Notch3 and Jagged2 contribute to gastric cancer development and to glandular differentiation associated with MUC2 and MUC5AC expression. Histopathology 2012; doi: 10.1111/j.1365-2559.2012.04274.x.

14. Sun Y, Gao X, Liu J, et al. Differential Notch1 and Notch2 expression and frequent activation of Notch signaling in gastric cancers. Arch Pathol Lab Med 2011; 135: 451-8.

15. Wang Z, Li Y, Sarkar FH. Notch signaling proteins: legitymate targets for cancer therapy. Curr Protein Pept Sci 2010; 11: 398-408.

16. Piazzi G, Fini L, Selgrad M, et al. Epigenetic regulation of Delta-Like 1 controls Notch1 activation in gastric cancer. Oncotarget 2011; 2: 1291-301.

17. Yeh TS, Wu CW, Hsu KW, et al. The activated Notch1 signal pathway is associated with gastric cancer progression through cyclooxygenase-2. Cancer Res 2009; 69: 5039-48.

18. Hsu KW, Hsieh RH, Huang KH. Activation of the Notch1/STAT3/Twist signaling axis promotes gastric cancer progression. Carcinogenesis 2012; 33: 1459-67.

19. Tseng YC, Tsai YH, Tseng MJ, et al. Notch2- induced COX-2 expression enhancing gastric cancer progression. Mol Carcinog 2012; 51: 939-51.

20. Wang Z, Aamir YL, Azmi AS, Banerjee S, Kong D, Sarkar FH. Targeting Notch signaling pathway to overcome drug resistance for cancer therapy. Biochim Biophys Acta 2010; 1806: 258-67. 
21. Miele L. Notch signaling. Clin Cancer Res 2006; 12: 1074-9.

22. Rizzo P, Osipo C, Foreman K, Golde T, Osborne B, Miele L. Rational targeting of Notch signaling in cancer. Oncogene 2008; 27: 5124-31

23. Shih I, Wang TL. Notch signaling, gamma-secretase inhibitors, and cancer therapy. Cancer Res 2007; 67: 1879-82.

24. Mao XY, Wang XG, Lu XJ, Xu L, Hang CB. COX-2 expression in gastric cancer and its relationship with angiogenesis using tissue microarray. World J Gastroenterol 2007; 13: 3466-71.

25. Murata H, Kawano S, Tsuji S, Tsuji M, Sawaoka H, Kimura Y, Shiozaki H, Hori M. Cyclooxygenase-2 overexpression enhances lymphatic invasion and metastasis in human gastric carcinoma. Am J Gastroenterol 1999; 94: 451-5.

26. Fosslien E. Review: molecular pathology of cyclooxygenase-2 in cancer-induced angiogenesis. Ann Clin Lab Sci 2001; 31: 325-48.

27. Ji Q, Hao X, Meng Y, Zhang M, DeSano J, Fan D, Xu L. Restoration of tumor suppressor miR-34 inhibits human p53-mutant gastric cancer tumorspheres. BMC Cancer 2008; 8: 266-78.

28. Wang Z, Li Y, Sarkar FH. Notch signaling proteins: legitymate target for cancer therapy. Curr Protein Pept Sci 2010; 11: 398-408.

29. Bommer GT, Gerin I, Feng Y, et al. P53-mediated activation of miRNA34 candidate tumorsuppressor genes. Curr Biol 2007; 17: 1298-307.

30. Chang TC, Wentzel EA, Kent OA, et al. Transactivation of miR-34a by p53 broadly influences gene expression and promotes apoptosis. Mol Cell 2007; 26: 745-52.

31. He C, Xiong J, Xu X, Lu W, Liu L, Xiao D, Wang D. Functional elucidation of MiR-34 in osteosarcoma cells and primary tumor samples. Biochem Biophys Res Commun 2009; 388: 35-40.

32. Kato M, Paranjape T, Muller RU, et al. The mir-34 microRNA is required for the DNA damage response in vivo in C. elegans and in vitro in human breast cancer cells. Oncogene 2009; 28: 2419-24.

33. Kozaki K, Imoto I, Mogi S, Omura K, Inazawa J. Exploration of tumorsuppressive microRNAs silenced by DNA hypermethylation in oral cancer. Cancer Res 2008; 68: 2094-105.

34. Lujambio A, Calin GA, Villanueva A, et al. A microRNA DNA methylation signature for human cancer metastasis. Proc Natl Acad Sci U S A 2008; 105: 13556-61.

35. Toyota M, Suzuki H, Sasaki Y, Maruyama R, Imai K, Shinomura Y, Tokino T. Epigenetic silencing of microRNA-34b/c and B-cell translocation gene 4 is associated with CpG island methylation in colorectal cancer. Cancer Res 2008; 68: 4123-32.

36. Tarasov V, Jung P, Verdoodt B, Lodygin D, Epanchintsev A, Menssen A, Meister G, Hermeking H. Differential regulation of microRNAs by $\mathrm{p} 53$ revealed by massively parallel sequencing: miR-34a is a p53 target that induces apoptosis and G1-arrest. Cell Cycle 2007; 6: 1586-93.

37. Wang Z, Li Y, Kong D, Ahmad A, Banerjee S, Fazlul H, Sarkar FH. Crosstalk between miRNA and Notch signaling pathways in tumor development and progression. Cancer Lett 2010; 292: 141-8.

\section{Address for correspondence}

\section{Marlena Brzozowa}

Chair and Department of Histology and Embryology

Medical University of Silesia

Jordana 19

41-808 Zabrze, Poland

e-mail:marlena.brzozowa@op.pl

Submitted: $\quad 6.03 .2012$

Accepted: $\quad 26.10 .2012$ 